\title{
Knowledge, attitude and intentions towards nursing profession among Chinese high school graduates in central China
}

\author{
Shuzhen Zhu*1, Jie $\mathrm{Hu}^{2}$, Kenneth J. Gruber ${ }^{3}$, Guangwu $\mathrm{Li}^{1}$, $\mathrm{Li} \mathrm{Li}^{4}$, Yuye $\mathrm{Ke}^{1}$ \\ ${ }^{1}$ Department of Nursing, Hubei University of Medicine, Shiyan City, Hubei Province, China \\ ${ }^{2}$ College of Nursing, The Ohio State University, United States \\ ${ }^{3}$ Center for Housing and Community Studies, The University of North Carolina at Greensboro, Greensboro, United States \\ ${ }^{4}$ Department of Nursing, Affiliated People's Hospital of Hubei University of Medicine, Shiyan City, Hubei Province, China
}

Received: July 16, 2021

DOI: $10.5430 /$ jnep.v12n2p72
Accepted: September 22, $2021 \quad$ Online Published: October 19, 2021

URL: https://doi.org/10.5430/jnep.v12n2p72

\begin{abstract}
Background and objective: Current nursing shortages and low willingness of young people to choose nursing as a career are of major concern in many countries. This study examined the knowledge, attitude and intention towards the nursing profession among high school graduates in China and factors associated with graduate' intention to enroll in nursing program.

Methods: A cross-sectional study was conducted using a random sampling. A total of 3764 high school graduates of selected schools in Central China participated in the study. Data were collected with online survey including demographics, knowledge of and attitude towards nursing and intention to choose nursing. Pearson's correlations and Hierarchical regression analyses were performed.

Results: Less than $10 \%$ of the participants expressed interest in a future career in nursing. Knowledge and attitude about nursing were positively associated with intention to study nursing. Both participants' education, family income and attitude significantly predicted intention to study nursing in the hierarchy regression model $(p<.001)$.

Conclusions: Recruitment and retention strategies need to focus on addressing improving knowledge about the roles of nurse among high school students. Nursing administrators and educators should provide information about nursing profession on Websites and social media or programs for high school students with early clinical exposure to nursing to increase their knowledge and change their attitudes toward nursing.
\end{abstract}

Key Words: Knowledge, Attitude, Intention, Chinese high school graduates

\section{INTRODUCTION}

Worldwide, the health care field has encountered severe nurse shortages. According to the World Health Organization reports, nurses and midwives are estimated to account for over $50 \%$ of a projected worldwide health workforce shortage by 2030 (World Health Organization. ${ }^{[1,2]}$ The percentage of new nurses in China reflects this downward trend. In the 2000's
China experienced a shortage of nearly 5 million nurses. ${ }^{[3]}$ while the numbers of registered nurses per 1,000 population increased from 1.52 in 2010 to 2.73 in $2018,{ }^{[4,5]}$ recent data indicate that the Central and West regions of China are facing a worsening nursing shortage. ${ }^{[6,7]}$ In addition to representing a reduced workforce, a shortage of nursing has negative effects on the stability of health care systems and the safety of

\footnotetext{
*Correspondence: Shuzhen Zhu; Email: shzh_zhu@163.com; Address: Department of Nursing, Hubei University of Medicine, Shiyan City, Hubei Province, China.
} 
patient care. ${ }^{[8,9]}$ In response to this situation, The State of the World's Nursing in 2020 has called for countries experiencing shortages to increase the total number of nurse graduates by an average of $8 \%$ per year. ${ }^{[2]}$ However, to accomplish this goal, nursing programs are facing great challenges in attracting qualified candidates, and many young people, especially high school graduates, including those in China are reluctant to choose nursing as a career. ${ }^{[10,11]}$

Career choice is a multi-factorial decision-making process that is influenced by personal intrinsic and extrinsic factors, ${ }^{[12,13]}$ and that intrinsic factors are a major contributor for choosing nursing. ${ }^{[14]}$ Studies on intention to enter nursing programs among teens and young adults find that interest tends to focus on personal factors, such as a desire to help others $^{[15,16]}$ and personal interest. ${ }^{[17,18]}$ The knowledge, attitude and practices (KAP) model suggests that practices (behaviors) are determined by the person's attitude and knowledge towards the behaviors. ${ }^{[19,20]}$ In the context of this model, the knowledge and attitude about nursing can be viewed as an individual's intrinsic aspects for a personal decision to choose nursing as a career.

In China, high school graduates choose majors in college application based on their scores on the National College Entrance Examination (NCEE). Students with high scores in the college entrance examination choose prestigious universities or popular major. Although the improvement in the image of the nursing professor and advancement in nursing education underwent tremendous positive change during the 1990s, ${ }^{[3]}$ the attraction of nursing as career choice has remained a relatively low preferred career option. This is because for many students who enroll in nursing programs do so because their college entrance examination scores are low limiting their education options. ${ }^{[21]}$ A consequence of this is that the field attracts students who are not highly motivated and interested in being nurses and who ultimately drop out at high rates. ${ }^{[22]}$ In contrast, students who selected nursing as their first choice were more likely to complete the nursing program. ${ }^{[23,24]}$

Since the high school graduates are the main source of the future nursing workforce in China, recruiting candidates with a high intention to pursue a career in nursing could reduce attrition and avoid further shortage. To improve recruitment of qualified and interested students into nursing it is important to identify factors associated with Chinese high school graduates' intention to enroll in nursing programs, particularly examine how the personal intrinsic factors (knowledge and attitude) would contribute to intention to enrolling in nursing programs. While a few of studies examined high school graduates' knowledge, perception, and willingness to enter nursing program in western countries, none has conducted in mainland China. A study that can provide valuable insights into the recruitment and retention strategies of high school graduates into nursing and help develop effective strategies for attracting high school graduates to study nursing in China is greatly needed. Therefore, the purpose of the study was to examine relationships among knowledge, attitudes and intention to study nursing among high school graduates in Central China.

\section{METHOD}

\subsection{Research design}

A cross-sectional study was conducted using an online survey to assess high school graduates' knowledge and attitude about the nursing profession and their intention to enroll in nursing program. The primary questions addressed in this study were:

- What were the differences between the demographic characteristics and intention to study nursing among high school graduates in mainland China?

- What were the relationships among knowledge of nursing, attitudes toward nursing and the intention to study nursing among high school graduates in mainland China?

- Were the knowledge of and attitude toward nursing predictors of Chinese high school graduates' intention to study nursing in mainland China?

\subsection{Setting and sample}

Participants were recruited from high school graduates by a random sampling method. Nine districts of school listings consisting of 7106 high school graduates were obtained from the Department of Education of Shiyan City in northwestern part of China.

The sample size was calculated in OpenEpi 2.3 software using a single population proportion calculation formula $\mathrm{n}=$ $[\mu \alpha 2 \mathrm{p}(1-\mathrm{p}) / \delta 2]^{[25]}$ (The proportion value $(p)$ was selected to be $10 \%$ based on previous studies that have reported that 10\%-20\% high school graduates choose nursing as an education option) The total calculated sample yielded 4,100 to represent large populations with $95 \%$ confidence level $(\mathrm{Z}=$ $1.96)$, with an error rate (d) of 5\% and assumption of $10 \%$ of students will choose to pursue a career in nursing, plus $10 \%$ non-response rate.

A non-proportionate sampling frame was computer generated. Inclusion criteria included: (1) high school graduates who had taken the National College Entrance Examination (Ministry of Education of the People's Republic of China), (2) able to read and speak Chinese, (3) volunteered to participate in the study. A total of 4,100 graduates $(57.7 \%$ of the total number of enrolled graduates) from a list of high school graduates in nine districts were invited to participate 
in the study. After survey participation was completed, the weighted data was generated based each list of high schools' graduates in nine districts to account for sampling design.

\subsection{Data collection and measures}

Recruitment flyers and a Web link to the online survey were distributed to the potential participants through coordinators in the institutions. The data were collected in July 2020. The online survey was imported to Questionnaire Star Platform and distributed through Web-based social media applications including WeChat and Tencent QQ (Tencent Holdings Limited, Shenzhen, China). It took participants approximately 10 to 15 minutes to complete the survey.

The Attitudes Toward Nursing Career Questionnaire (ATNCQ ${ }^{[26-28]}$ which collects demographic data, nursing knowledge, attitudes and intentions about studying nursing was used for obtaining the data for this study. The questionnaire includes 12 items examining the students' knowledge about nursing (including nature, role of nursing and function (e.g., nursing career involves caring for patients"); nine items regarding their attitudes towards nursing (e.g., "according to the public, only women are suitable to be nurses); and eight items on intention to study nursing (e.g., "I am interested in being a nurse" ). Responses to the items are measured using a 5-point Likert-type scale measuring strength of with one for 'strongly disagree' and five for 'strongly agree'. Higher scores indicate better knowledge and positive attitudes, and greater likelihood to choose nursing as their education major. The test-retest reliability for the three subscales (knowledge, attitude and intention scale) included in the ATNCQ range from .75 to .84 , and internal consistency from .92 to $\left..97^{[26-28]}\right)$. In the current study, the Cronbach's alphas were $.89, .91$ and .91 for knowledge, attitude and intention respectively, and the mean scores of the subscale were used in the analysis.

\subsection{Ethical considerations}

Ethical approval was granted by the Human Research Ethics Committees (HRECs) of the University and the High Schools ethics board of all participating high schools (approval number: 2019-07-023). Both participants and their parents were informed about the study purpose in a participation information form in the Web link. Written informed consent was obtained from participants and their parents or guardian prior to the study. Participation anonymity of all participants was assured and confidentiality of data was maintained throughout the study.

\subsection{Data analysis}

Descriptive statistical statistics were used to describe demographic characteristics of the participants, knowledge, attitudes and intention about nursing. Independent $t$-test was used to examine between demographics and intention to study nursing. Pearson's correlations were used to examine relationships among knowledge, attitudes and intention. Hierarchical regressions were conducted to examine predictors of intention. Demographic variables of parents' occupation and education level, family income, were coded as dummy variables in the regression models. All tests were two-tailed and significance were estimated at $p<.05$. Data were performed using SPSS Statistics 22. ${ }^{29]}$

\section{RESULTS}

\subsection{Demographic information}

A total of 4,100 individuals were invited to participant in the study, and 3,764 participants returned the survey, yielding a response rate of $91.8 \%$. The mean age was 18.3 years $(\mathrm{SD}=5.8)$, age ranged between $17-19$ years and $54.6 \%$ of the sample were female. Less than $10 \%$ of the participants reported a preference for nursing as their future job. In addition, the majority of participants reported their parents were a high school and above graduate and had a non-medical occupation. With regard to family income, most of the participants $(77.3 \%)$ came from low-middle income families (monthly household income $<5,000$ RMB (US \$700)/month (see Table 1).

\subsection{Knowledge, attitude and intention scores}

In general, the participants had good knowledge of the nursing profession reporting a mean knowledge score of $3.81 \pm$ .396. The majority of the participants either strongly agreed or agreed that nurses provided comfortable environments for patients $(85.0 \%)$, assisted doctors in taking care of patients $(83.2 \%)$ and that nursing involved caring for patients $(80.1 \%)$. However, less than half of the respondents knew that nurses provided education for patients regarding their illnesses $(45.2 \%)$ or were involved in health promotion activities $(43.1 \%)$. The mean attitude scores on attitude regarding nursing profession were $3.35 \pm .609$ (see Table 1). A majority agreed that the nursing profession was a job for females (85.7\%), only a little over one-third $(38.0 \%)$ thought that nursing was a very interesting job and only $37.2 \%$ reported being was comfortable with the idea of being a nurse. The mean level of intention to study nursing of respondents was relatively low $2.72 \pm .618$ (see Table 1 ). This was reflected in the finding of less than a fifth $(16.2 \%)$ of the respondents were interested in nursing, despite almost three-fourths (70.1\%) of the respondents reported finding satisfaction in seeing people getting better. In addition, $50 \%$ of the respondents reported that their parents would not encourage them choose nursing as their career. 
Table 1. Demographic characteristics and major study variables $(\mathrm{N}=3,764)$

\begin{tabular}{|c|c|c|}
\hline Variable & Frequency/Mean & Percent/SD \\
\hline \multicolumn{3}{|l|}{ Gender } \\
\hline Female & 1,933 & 51.4 \\
\hline Age & 18.3 & 5.8 \\
\hline \multicolumn{3}{|l|}{ School district } \\
\hline Urban & 3,202 & 85.1 \\
\hline Rural & 562 & 14.9 \\
\hline \multicolumn{3}{|l|}{ Job preference } \\
\hline Nursing & 371 & 9.9 \\
\hline Others & 3,393 & 90.1 \\
\hline \multicolumn{3}{|l|}{ Parent connection with nursing } \\
\hline Yes & 40 & 1.1 \\
\hline No & 3,724 & 98.9 \\
\hline \multicolumn{3}{|c|}{ Parent connection with medical field } \\
\hline Yes & 493 & 13.1 \\
\hline No & 3,271 & 86.9 \\
\hline \multicolumn{3}{|l|}{ Fathers' education } \\
\hline High school diploma or below & 1,702 & 45.2 \\
\hline College education or more & 2,062 & 54.8 \\
\hline \multicolumn{3}{|l|}{ Mothers' education } \\
\hline High school diploma or below & 2,045 & 54.3 \\
\hline College education or more & 1,719 & 45.7 \\
\hline \multicolumn{3}{|l|}{ Monthly family income, yuan } \\
\hline Low & 2,268 & 60.3 \\
\hline High & 1,496 & 39.7 \\
\hline Knowledge & 3.81 & .396 \\
\hline Attitude & 3.35 & .609 \\
\hline Intention & 2.72 & .618 \\
\hline
\end{tabular}

Differences between demographic characters and intention (see Table 2), indicated that father's education level ( $t=$ 5.509, $p=.000)$, mother's education level $(t=5.662, p=$
$.000)$, and family income $(t=2.092, p=.043)$ were significant correlated to high school graduates' intention to study nursing.

In Table 3, Pearson's correlations were found to be associated with participants' knowledge about nursing career $(\mathrm{r}=$ $.095, p<.01)$ and their attitude towards nursing career $(\mathrm{r}=$ $.371, p<.01)$ were significant correlated to their intention to study nursing. In addition, knowledge of nursing career was also correlated to their attitude towards nursing career $(\mathrm{r}=$ $.14, p<.01)$.

\subsection{Prediction of intent to enter a nursing program}

Table 4 presents the result of hierarchical regression analyses predicting the intention to enter nursing programs. The independent variables (demographic variables) were entered into the first model, following the knowledge of and attitude toward nursing career added in Model 2. The intention was the dependent variable in two models. In the final model, the attitudes toward nursing career significantly predicted intention to study nursing $\left(R^{2}=.145, R^{2}\right.$ Change $=.136 \mathrm{~F}$ $(5)=172.212, p<.001)$ ) after adjusting for the effect of demographic variables. The final model accounted for $19.4 \%$ of variance in intention to study nursing (see Table 4).

\section{Discussion}

While recruiting high school new graduates to nursing programs will contribute to alleviating nursing shortage, factors influencing high school students' intention to choose nursing are important for development of national strategies to address nursing shortage.

Table 2. Differences between demographic characters and intentions among high school graduates $(\mathrm{N}=3,764)$

\begin{tabular}{|c|c|c|c|c|c|c|c|c|c|c|}
\hline \multirow{2}{*}{ Grouping Variables } & & \multicolumn{3}{|l|}{ Knowledge } & \multicolumn{3}{|l|}{ Attitude } & \multicolumn{3}{|l|}{ Intention } \\
\hline & & Mean (SD) & $t$ & $p$ & Mean (SD) & $t$ & $p$ & Mean (SD) & $t$ & $p$ \\
\hline \multirow{2}{*}{ Gender } & Female & $3.83(.404)$ & 3.724 & .000 & $3.39(.602)$ & 4.133 & .000 & $2.73(.593)$ & 1.411 & .158 \\
\hline & Male & $3.79(.386)$ & & & $3.31(.613)$ & & & $2.70(.642)$ & & \\
\hline \multirow{2}{*}{ School district } & Urban & $3.81(.369)$ & 2.536 & .011 & $3.35(.596)$ & .008. & 994 & $2.72(.624)$ & .467. & .640 \\
\hline & Rural & $3.77(.396)$ & & & $3.35(.678)$ & & & $2.71(.582)$ & & \\
\hline \multirow{2}{*}{$\begin{array}{l}\text { Parent connection with } \\
\text { nursing }\end{array}$} & Yes & $3.88(.464)$ & -.971 & .337 & $3.66(.369)$ & -3.193 & .001 & $2.79(.498)$ & -.885 & .381 \\
\hline & No & $3.81(.394)$ & & & $3.35(.610)$ & & & $2.72(.619)$ & & \\
\hline \multirow{2}{*}{$\begin{array}{l}\text { Parent connection with } \\
\text { medical field }\end{array}$} & Yes & $3.87(.549)$ & -3.383 & .001 & $3.33(.677)$ & .614 & .521 & $2.73(.673)$ & -.271 & .786 \\
\hline & No & $3.80(.366)$ & & & $3.35(.598)$ & & & 2.72 (609.) & & \\
\hline \multirow{2}{*}{ Father's education } & Low & $3.81(.407)$ & -.262 & .794 & $3.36(.598)$ & 1.262 & .207 & $2.78(.594)$ & 5.059 & $.000 * *$ \\
\hline & High & $3.81(.386)$ & & & $3.34(.617)$ & & & $2.67(.633)$ & & \\
\hline \multirow{2}{*}{ Mother's education } & Low & $3.81(.402)$ & -.478 & .633 & $3.36(.597)$ & 1.680 & .093 & $2.77(.579)$ & 5.662 & $.000 * *$ \\
\hline & High & $3.81(.388)$ & & & $3.33(.622)$ & & & $2.66(.656)$ & & \\
\hline \multirow{2}{*}{ Monthly family income } & Low & $3.82(.392)$ & 2.307 & .021 & $3.38(.587)$ & 3.330 & .001 & $2.74(.520)$ & 2.092 & $.043 *$ \\
\hline & High & $3.79(.400)$ & & & $3.31(.639)$ & & & $2.69(.741)$ & & \\
\hline
\end{tabular}

Note. ${ }^{*} p \leq .05 ; * * \leq .01$; low of fathers' and mother education was high school diploma or below and high was college education or more); low of monthly family income was $\leq 4,000$ RMB and high was more than 4,000 RMB (US \$600)/month. 
Table 3. Pearson's correlations between knowledge, attitude and intentions among high school graduates $(\mathrm{N}=3,764)$

\begin{tabular}{llll}
\hline Variable & Knowledge & Attitude & Intention \\
\hline Knowledge & 1 & $.214^{* *}$ & $.095^{* *}$ \\
Attitude & & 1 & $.371^{* *}$ \\
Intention & & & 1 \\
\hline Note. ${ }^{*} p \leq .05 ; * p \leq .01$. & &
\end{tabular}

The findings showed that Chinese high school graduates had relatively high levels of knowledge about but negative attitudes toward nursing. The students' negative attitudes towards nursing are likely to be a strong factor accounting for the low level of intention to study nursing.

\subsection{Knowledge, attitude and intention}

Consistent with previous studies examining high school students' interest in a nursing career, participants expressed low intention to study nursing in our study. Less than $10 \%$ identified nursing as their future occupation. Cho et al. ${ }^{[30]}$ found that among 2,456 high school students in Korea less than 3\% $(n=40)$ entered nursing schools. Social image and status of nursing in $\mathrm{China}^{[3]}$ are the major factors contributing to the lack of interest in nursing career in high school graduates. Therefore, it is necessity for nursing administrators and managers to provide more information about nurse professional status for the public, and increasing the attractiveness of nursing as a career, especially in central areas in mainland China. ${ }^{[7]}$

Table 4. Hierarchical regression analysis of predictor for graduates' intentions to study nursing $(\mathrm{N}=3,764)$

\begin{tabular}{|c|c|c|c|c|c|c|c|}
\hline Variable & Beta & $t$ & Sig & $F$ & $p$ & $\overline{R^{2}}$ & $R^{2}$ Change \\
\hline Model 1 & & & & 11.995 & .000 & .009 & .009 \\
\hline Fathers' education level X1 (low) & ref. & & & & & & \\
\hline Fathers' education level X2 (high) & -.020 & -.717 & .474 & & & & \\
\hline Mothers' education level X1 (low) & ref. & . & . & & & & \\
\hline Mothers' education level X2 (high) & -.075 & -2.749 & .006 & & & & \\
\hline Monthly family income X1 (low) & ref. & & & & & & \\
\hline Monthly family income X2 (high) & -.029 & -1.781 & .075 & & & & \\
\hline Model 2 & & & . & 127.212 & .000 & .145 & 0.136 \\
\hline Fathers' education level X1 (low) & ref. & & & & & & \\
\hline Fathers' education level X2 (high) & -.024 & -.937 & .349 & & & & \\
\hline Mothers' education level X1 (low) & ref. & & & & & & \\
\hline Mothers' education level X2 (high) & -.062 & -2.458 & .014 & & & & \\
\hline Monthly family income X1 (low) & ref. & & & & & & \\
\hline Monthly family income X2 (high) & -.009 & -.569 & .569 & & & & \\
\hline Knowledge & .007 & .446 & .656 & & & & \\
\hline Attitude & 367 & 23.558 & .000 & & & & \\
\hline
\end{tabular}

Note. Control variables entered at Model 1 were retained in all stages of analyses and final hierarchical regression model included only those variables presented in this table; low of fathers' and mother education was high school diploma or below and high was college education or more); low of monthly family income was $\leq 4,000 \mathrm{RMB}$ and high was more than 4,000 RMB (US \$600)/month; ref = reference group.

The findings of this study also revealed that high school graduates perceived themselves as having a relatively high level of knowledge about the nursing profession but were unfamiliar with multiple nurses roles. High school graduates were less aware of current trends and developments in nursing, such as patient education, health promotion and multidisciplinary collaboration in patient care. ${ }^{[26]}$ Nursing students at the beginning of their program had inaccurate knowledge about the profession and knew very little about the nursing profession. ${ }^{[27,31]}$ Providing students with multifaceted opportunities to obtained accurate information about the multiple roles of nurses may contribute to the positive perceptions of a nursing profession in contemporary health care. ${ }^{[32]}$

Overall, participants had a relatively negative attitude toward nursing profession, as reflected in the findings of the study that only one-third (38.0\%) thought that nursing was a very interesting job and they felt comfortable with the conception of being a nurse. The majority of the participants (85.7\%) believed that the nursing as a female profession. The findings were consistent with Sun et al. ${ }^{[33]}$ that students perceived the caring nature of nursing as the domestic roles of women and a typical female profession by Chinese high school students. Numerous studies have shown that the public has traditional 
gender stereotyped views of the nursing profession that persist to this day around the word including China. ${ }^{[34]}$ Changes are needed to improve the public' image in the current healthcare environment by qualified nurses and social media. ${ }^{[35]}$

\subsection{Relationships among demographic characteristic, knowledge, attitude and intention about nursing}

Among demographic characteristics, household income was associated with students' intention to choose nursing major. The students from relatively higher household income levels were significantly less likely to choose nursing major than those from lower income families. Also, Law and Arthur ${ }^{[36]}$ found that negative correlations between family income and intention to study nursing. Although nursing is commonly perceived in China as a feminine profession, our study failed to support the relationship between the gender of students and their intention to enter nursing. Yang et al. ${ }^{[37]}$ also found that gender was not perceived as a barrier for Taiwanese males and they believed that nursing was a profession suitable for both women and men. Other finding indicated that being a female was a common attribute among students who intended to choose a nursing career. ${ }^{[15]}$ An explanation of the findings might be related to the nursing image-building campaign in China, especially during the COVID-19 outbreak that media coverage highlighted nurses' roles in combating the pandemic, portraying nurses as a selfless/angelic hero with knowledge, skills and nursing as a profession with autonomy collaborating with health care team for patient care in clinical settings. Therefore, nursing managers should continue to promote positive images of nurses though social media to influence high school students' decision to choose nursing as a career.

Career choice theory indicates that parents, family and significant others play an important role in the career choice process of school pupils. ${ }^{[31,38]}$ Our study found that participants' parents' education levels were associated with their intention. The findings of our study are consistent with previous research, ${ }^{[39]}$ that family's high educational attainment, having a nurse in the family or relatives, influence of friends and guidance of teachers in career choices greatly impacted students' choice of nursing as a profession. Other studies found that students who choosing nursing major based on their own preference, ${ }^{[30]}$ and the opinions of family members had little influence on their preferences to nursing. ${ }^{[18]}$ An explanation is that nursing has still been viewed as a lowpaying and low-status job in China. Especially, parents who are in nursing generally expect their children to choose a career perceived as a prestigious profession in Chinese society and they would not encourage them pursing nursing as a career. Future studies need to explore perceptions of high

Published by Sciedu Press school students and their patients on nursing profession.

Similar to prior studies, we found that knowledge was positively associated with participants' intention to study nursing. Students who had more accurate knowledge about nursing were greater willingness to enroll in nursing programs. ${ }^{[40]}$

In contrast to previous study found that knowledge was not associated with intention to study nursing among high school students or pre-clinical nursing students. ${ }^{[27,41]}$ High school graduates who lack knowledge about nursing were an important determinant of their attitude which in turn relates to their intention to study nursing. Thus, nursing programs at universities should provide more information and avenues for high school graduates to learn about the nursing career, such as summer nursing camps. In addition, connections between university nursing programs and local high schools should provide students with early clinical exposure to the challenges of nursing. Providing clinical experiences and volunteer programs in nursing will assist high school students in obtaining comprehensive knowledge about nursing and understanding of nursing as a profession. It may help students gain their insights into the skills and attitudes required for the profession, and ultimately increase students' motivation to pursue nursing as a career. ${ }^{[42]}$

\subsection{Predictors of intention to study nursing}

Attitude towards nursing was an important factor and the crucial determinants for Chinese high school graduates' intention to study nursing in the current study. The findings of the study are consistent with previous study that students had low intention to enter nursing due to negative attitude towards nursing. ${ }^{[27]}$ An additional explanation of these findings is that negative attitudes might have been shaped by lack of knowledge about the roles of nursing. ${ }^{[43]}$ Moreover, findings of our study found there was a positive relationship between knowledge, attitude and intention. Therefore, strategies aimed at increasing knowledge and fostering positive attitudes may contribute to increasing of the intention to study nursing.

Our study found that fathers' education and family income were predictors of individuals' intention to enroll in nursing programs among high school graduates, whereas those who had high monthly household income and their parents had high education level were less likely to choosing nursing as a career. The findings of the study may be related to the social prejudice toward nurses in China where nursing has been viewed as a female occupation with low social status. ${ }^{[44]}$ Nursing in traditional Chinese culture is viewed as a "serving" occupation that only those with low social status would take care of patients. Moreover, the Social Cognitive Theory indicates that sociocultural and environmental contexts could 
influence individual in career decision-making. ${ }^{45,46]}$ The results suggest that a future intentions strategies for change students' intention to choosing nursing major should focus on high school students who come from high income families and those parents had high education achieved conditions in mainland China.

However, due to attitude toward nursing explains less than $20 \%$ of the variation in high school graduates' intention to choose nursing as their major in the current study, there are other potential dimensions may exist beyond the knowledge of and attitude towards nursing. The low social image and status of nursing was an important barrier among high school graduates interested in a nursing career in China. ${ }^{[33]}$ Also, the majority of the participates perceived nursing is a job for females and consider nurses as a subordinate to the work of physicians in taking care of patients. Therefore, it is important for nursing organizations to create a positive public image of nursing as a profession in China.

\subsection{Limitations of the study}

The study has several limitations. The sample of high school graduates was collected from a single, although very large, region of nine high schools located in the same province in Central China, the results therefore may not be generalizable to other high school graduates with different sociocultural backgrounds. Additionally, the design of the present study is cross-sectional that would only provide a snapshot in time, limiting the ability to draw valid conclusions about any associations or possible causality. Thus, it is recommended that future studies be conducted with semi-structured interviews to explore the perceptions of intention to choose nursing as a future career choice among high school students and their parents, as well as longitudinal studies to allow for better understanding of students' career intention changes over time to strengthen the causal inferences. ${ }^{[47]}$

\section{Conclusion}

Given the critical nursing shortage globally, the number of high school graduates choosing nursing programs continue to decrease will aggravate nursing shortages in China. Programs should be developed to provide information about the roles of professional nursing, create the image of nursing, and promote positive attitude towards nursing career for the public. ${ }^{[48]}$ Collaborations between School of Nursing, and local high schools could provide opportunities for high school students with early clinical exposure to nursing. Websites and social media could serve as a platform for students and their parents providing information about nursing profession. ${ }^{[49]}$ Nursing schools also should identify high school graduates who are interested in studying nursing at the beginning of the career/major selection process that could contribute to decreasing attrition. ${ }^{[24]}$

\section{CONFlicts OF INTEREST Disclosure}

The authors declare that there is no conflict of interest.

\section{REFERENCES}

[1] World Health Organization. Nursing and midwifery: Fact sheet. 2018 Available from: http://www . who.int/mediacentre/factshee ts/nursing-midwifery/en/

[2] World Health Organization. State of the World's Nursing Report-2020 and The State of the World's Nursing 2020, News release Geneva 2020. Available from: https://www. who.int/campaigns/year - of-the-nurse-and-the-midwife-2020

[3] Yun H, Jie S, Anli J. Nursing shortage in China: State, causes, and strategy. Nurs Outlook. 2010; 58(3): 122-128. PMid:20494686 https://doi.org/10.1016/j.outlook.2009.12.002

[4] Wu Q, Zhao L, Ye XC. Shortage of healthcare professionals in China. BMJ (Clinical research ed.). 2016; 354: i4860. PMid:27659864 https://doi.org/10.1136/bmj.i4860

[5] Zhou M, Zhao L, Kong N, et al. What Caused Seriously Shortage of Chinese Nurses?. Iran J Public Health. 2018; 47(7): 1065-1067.

[6] Wu J, Yang Y. Inequality trends in the demographic and geographic distribution of health care professionals in China: Data from 2002 to 2016. Int J Health Plann Manage. 2019; 34(1): e487-e508. https://doi.org/10.1002/hpm. 2664

[7] You LM, Ke YY, Zheng J, et al. The development and issues of nursing education in China: a national data analysis. Nurse Educ Today.
2015; 35(2): 310-314. PMid:25456256 https://doi.org/10.1 $016 / j$.nedt .2014 .10 .004

[8] ICN-International Council of Nursing. ICN Asia Nursing Workforce Forum. Nursing Workforce Profile Database Summary. Available from: http://www.icn.ch/images/stories/documents/ pillars/sew/DATASHEET_ALL_COUNTRIES_AWFF_2013.pdf

[9] You LM, Aiken LH, Sloane, DM, et al. Hospital nursing, care quality, and patient satisfaction: cross-sectional surveys of nurses and patients in hospitals in China and Europe. Int J Nurs Stud. 2013; 50(2): 154-161. PMid:22658468 https://doi.org/10.1016/j . i jnurstu. 2012.05.003

[10] International Council of Nurses. An Ageing Nursing Workforce. 2008; ICN, Geneva.

[11] World Health Organization. Transformative scale up of health professional education: an effort to increase the numbers of health professionals and to strengthen their impact on population health. WHO, Geneva. 2011

[12] Hodkinson P, Sparkes AC. Careership: A sociological theory of career decision making. British Journal of Sociology of Education. 1997; 18: 29-44. https://doi.org/10.1080/01425699701801 02

[13] Puertas EB, Arósquipa C, Gutiérrez D. Factors that influence a career choice in primary care among medical students from high-, middle-, 
and low-income countries: a systematic review. Rev Panam Salud Publica. 2013; 34(5): 351-358.

[14] Wu LT, Low MM, Tan KK, et al. Why not nursing? A systematic review of factors influencing career choice among healthcare students. Int Nurs Rev. 2015; 62(4): 547-562. PMid:26572517 https://doi.org/10.1111/inr.12220

[15] Başkale H, Serçekuş P. Nursing as career choice: perceptions of Turkish nursing students. Contemporary Nurse. 2015; 51(1): 515. PMid:26073696 https://doi.org/10.1080/10376178. 201 5.1025469

[16] Usher K, West C, Macmanus M, et al. Motivations to nurse: an exploration of what motivates students in Pacific Island countries to enter nursing. Int J Nurs Pract. 2013; 19(5): 447-454. PMid:24093735 https://doi.org/10.1111/ijn.12095

[17] Halperin O, Mashiach-Eizenberg M. Becoming a nurse - A study of career choice and professional adaptation among Israeli Jewish and Arab nursing students: A quantitative research study. Nurse Educ Today. 2014; 34: 1330-1334. PMid:24269141 https://doi.org/ $10.1016 / j$. nedt .2013 .10 .001

[18] Jirwe M, Rudman A. Why choose a career in nursing? J Adv Nurs. 2012; 68(7): 1615-1623. PMid:22435896 https://doi .org/10.1 $111 / j .1365-2648.2012 .05991 . x$

[19] Alzghoul BI, Abdullah NA. Pain Management Practices by Nurses: An Application of the Knowledge, Attitude and Practices (KAP) Model. Glob J Health Sci. 2015; 8(6): 154-160. PMid:26755474 https://doi.org/10.5539/gjhs.v8n6p154

[20] Tachfouti N, Slama K, Berraho M, et al. The impact of knowledge and attitudes on adherence to tuberculosis treatment: a case-control study in a Moroccan region. Pan Afr Med J. 2012; 12: 52.

[21] Gao Y, Cheng S, Madani C, et al. Educational experience of male students in a baccalaureate nursing program in China. Nurse Educ Pract. 2019; 35: 124-129. PMid:30785064 https://doi.org/10 $.1016 / j$.nepr.2019.02.006

[22] Wang Y. Investigation on attrition of nursing undergraduates in universities. China General Nurse, 2011; 3: 741-742.

[23] Kukkonen P, Suhonen R, Salminen L. Discontinued students in nursing education - Who and why?. Nurse Educ Pract. 2016; 17: 67-73. PMid:26774864 https://doi.org/10.1016/j.nepr.2015.12 .007

[24] Salamonson Y, Everett B, Cooper M, et al. Nursing as first choice predicts nursing program completion. Nurse Educ Today. 2014; 34(1): 127-131. PMid:23142172 https://doi.org/10.1016/j. nedt.2012.10.009

[25] Kleinbaum DG, Kupper LL, Morgenstern H. Epidemiologic Research. Principles and Quantitative Methods. 1982. Wadsworth, Belmont, CA: Lifetime Learning Publications.

[26] Al-Omar, BA. Knowledge, attitudes and intention of high school students towards the nursing profession in Riyadh city, Saudi Arabia. Saudi Med J. 2004; 25 (2): 150-155.

[27] Hatamleh WA, Sorio EH. Knowledge, attitude and intention towards nursing profession among pre-clinical students. Journal of Health Specialties. 2017; 5: 135-141. https://doi.org/10.4103/jhs . JHS_154_16

[28] Rossiter JC, Foong A, Chan PT. Attitudes of Hong Kong high school students towards the nursing profession. Nurse Educ Today. 1999; 19(6): 464-471. PMid:10693494 https://doi .org/10.1054/ne dt.1999.0331

[29] IBM SPSS Statistics for Windows, Version 22.0. IBM Corp., Armonk, NY.

[30] Cho SH, Jung SY, Jang S. Who enters nursing schools and why do they choose nursing? A comparison with female non-nursing students using longitudinal data. Nurse Educ Today. 2010; 30(2): 180-186.
PMid:19682773 https://doi.org/10.1016/j.nedt.2009.07 .009

[31] Glerean N, Hupli M, Talman K, et al. Perception of nursing profession-focus group interview among applicants to nursing education. Scand J Caring Sci. 2019; 33(2): 390-399. PMid:30604883 https://doi.org/10.1111/scs. 12635

[32] Rubbi I, Pasquinelli G, Cremonini V, et al. Does student orientation improve nursing image and positively influence the enrolment of nursing students in the University? An observational study. Acta Biomed. 2019; 90(6-S): 68-77. PMiD: 31292417 https : //doi.org/10.23750/abm.v90i6-S.8568

[33] Sun YM, Jiang H, Feng ZC, et al. Investigation on senior high school students' intention to study nursing and the contributing factors. Chinese Journal of Nursing Education, 2010; 7: 390-392.

[34] ten Hoeve Y, Jansen G, Roodbol P. The nursing profession: public image, self-concept and professional identity. A discussion paper. J Adv Nurs. 2014; 70(2): 295-309. PMid:23711235 https: //doi.org/10.1111/jan.12177

[35] Gill J, Baker C. The Power of Mass Media and Feminism in the Evolution of Nursing's Image: A Critical Review of the Literature and Implications for Nursing Practice. J Med Humanit. 2019 PMid:31713004 https://doi .org/10.1007/s10912-019-095 78-6

[36] Law W, Arthur D. What factors influence Hong Kong school students in their choice of a career in nursing?. Int J Nurs Stud. 2003; 40(1): 23-32. PMid:12550147 https://doi.org/10.1016/S0020-748 9(02) 00029-9

[37] Yang CI, Gau ML, Shiau SJ, et al. Professional career development for male nurses. J Adv Nurs. 2004; 48(6): 642-650. PMid:15548255 https://doi.org/10.1111/j.1365-2648.2004.03252.x

[38] Miller K, Cummings G. Gifted and talented students' career aspirations and influences: a systematic review of the literature. Int J Nurs Educ Scholarsh. 2009; 6: Article 8. PMid:19341358 https://doi.org/10.2202/1548-923X.1667

[39] Degazon CE, Ben Natan M, Shaw HK et al. Multi-ethnic high school students' perceptions of nursing in the USA and Israel: a descriptive quantitative study. Nurse Educ Today. 2015; 35(1): 57-62. PMid:24973335 https: //doi.org/10.1016/j.nedt.2014.05 .016

[40] Atance J Mickalis M, Kincade B. Educational Intervention in a Medically Underserved Area. J Am Osteopath Assoc. 2018; 118(4): 219-224. PMid:29582056 https://doi.org/10.7556/jaoa.2 018.047

[41] Neilson GR, Jones MC. What predicts the selection of nursing as a career choice in 5th and 6th year school students?. Nurse Educ Today. 2012; 32(5): 588-593. PMid:21852026 https://doi.org/10.1 016/j.nedt. 2011.06.011

[42] Neilson GR, McNally JG. Not choosing nursing: work experience and career choice of high academic achieving school leavers. Nurse Educ Today. 2010; 30(1): 9-14. PMid:19560236 https: //doi.org/10.1016/j.nedt.2009.05.007

[43] Zhang LF, You LM, Liu K, et al. The association of Chinese hospital work environment with nurse burnout, job satisfaction, and intention to leave. Nurs Outlook. 2014; 62: 128-137. PMid:24345617 https://doi.org/10.1016/j.outlook.2013.10.010

[44] Zhang HF, Liu YH, Yang Y, et al. The influencing factors of nurses' turnover tendency. Chinese Journal Nursing. 2015; 50: 155-160.

[45] Bandura A. Social Foundations of Thought and Action: A Social Cognitive Theory. Prentice Hall, Englewood Cliffs, NJ. 1986

[46] Lent RW, Brown SD. Social cognitive approach to career development: an overview. Career Development Quarterly. 1996; 
44: 310-322. https://doi.org/10.1002/j.2161-0045.1996 .tb00448.x

[47] Price SL, McGillis Hall L, Angus JE, et al. Choosing nursing as a career: a narrative analysis of Millennial nurses' career choice of virtue. Nurs Inq. 2013; 20(4): 305-316. PMid:23551958 https : //doi.org/10.1111/nin.12027
[48] Dik BJ, Duffy RD. Calling and vocation at work: Definitions and prospects for research and practice. Counseling Psychologist. 2009; 37: 424-450. https://doi .org/10.1177/0011000008316430

[49] Shatto B, Erwin K. Moving on From Millennials: Preparing for Generation Z. J Contin Educ Nurs. 2016; 47(6): 253-254 PMid:27232222 https://doi .org/10.3928/00220124-20160 518-05 